University of Nebraska - Lincoln

DigitalCommons@University of Nebraska - Lincoln

$11-16-2004$

\title{
The Contribution of Executive Functions to Emergent Mathematic Skills in Preschool Children
}

\author{
Kimberly Espy \\ University of Nebraska-Lincoln, kespy2@unl.edu \\ Melanie D. McDiarmid \\ Southern Illinois University School of Medicine, melanie-nelson@ouhsc.edu \\ Mary F. Cwik \\ Southern Illinois University School of Medicine, mcwik1@jhu.edu \\ Melissa Meade Stalets \\ Southern Illinois University School of Medicine \\ Arlena Hamby \\ Southern Illinois University School of Medicine \\ See next page for additional authors
}

Follow this and additional works at: https://digitalcommons.unl.edu/dcnlfacpub

Part of the Neurosciences Commons

Espy, Kimberly; McDiarmid, Melanie D.; Cwik, Mary F.; Stalets, Melissa Meade; Hamby, Arlena; and Senn, Theresa E., "The Contribution of Executive Functions to Emergent Mathematic Skills in Preschool Children" (2004). Developmental Cognitive Neuroscience Laboratory - Faculty and Staff Publications. 7. https://digitalcommons.unl.edu/dcnlfacpub/7

This Article is brought to you for free and open access by the Developmental Cognitive Neuroscience Laboratory at DigitalCommons@University of Nebraska - Lincoln. It has been accepted for inclusion in Developmental Cognitive Neuroscience Laboratory - Faculty and Staff Publications by an authorized administrator of DigitalCommons@University of Nebraska - Lincoln. 
Authors

Kimberly Espy, Melanie D. McDiarmid, Mary F. Cwik, Melissa Meade Stalets, Arlena Hamby, and Theresa E. Senn 


\title{
The Contribution of Executive Functions to Emergent Mathematic Skills in Preschool Children
}

\author{
Kimberly Andrews Espy, Melanie M. McDiarmid, \\ Mary F. Cwik, Melissa Meade Stalets, Arlena Hamby, \\ and Theresa E. Senn \\ Department of Family and Community Medicine \\ Southern Illinois University School of Medicine
}

\begin{abstract}
Mathematical ability is related to both activation of the prefrontal cortex in neuroimaging studies of adults and to executive functions in school-age children. The purpose of this study was to determine whether executive functions were related to emergent mathematical proficiency in preschool children. Preschool children ( $N=$ 96) were administered an executive function battery that was reduced empirically to working memory (WM), inhibitory control (IC), and shifting abilities by calculating composite scores derived ftom principal component analysis. Both WM and IC predicted early arithmetic competency, with the observed relations robust after controlling statistically for child age, maternal education, and child vocabulary. Only IC accounted for unique variance in mathematical skills, after the contribution of other executive functions were controlled statistically as well. Specific executive functions are related to emergent mathematical proficiency in this age range. Longitudinal studies using structural equation modeling are necessary to better characterize these ontogenetic relations.
\end{abstract}

Recent findings from functional imaging studies in adults highlight the role of the prefrontal cortex in mathematical performance, particularly in actual mathematical calculation (Fullbright et al., 2000; Gruber, Indefrey, Steinmetz, \& Kleinschmidt, 2001; Menon, Riveria, White, Glover, \& Reiss, 2000; Zago et al., 2001) or reasoning (Prabhakaran, Rypma, \& Gabrieli, 2001). In children, impair-

Requests for reprints should be sent to Kimberly Andrews Espy, Department of Family and Commurity Medicine, MC 6503, Southem Illinois University School of Medicine, 600 Agriculture Dr.. Carbondale, IL 62901-6503. E-mail: kespy@siumed.edu 
ments in arithmetic skills have been related to frontal activation $(\mathrm{H}$. S. Levin, Scheller, et al., 1996; Miles \& Stelmack, 1994); however, such studies have not been conducted in normally-developing youngsters to date.

In school-age children and adolescents, mathematical skills also are related, at least in part, to executive functioning (Bull \& Scerif, 2001; Cirino, Morris, \& Morris, 2002; Gathercole \& Pickering, 2000; McLean \& Hitch, 1999). In some of these studies, the central importance of working memory (WM) has been identified (e.g., Gathercole \& Pickering, 2000; McLean \& Hitch, 1999). However, other executive functions also are related to mathematical proficiency. In a sample of 122 nine-year-old children who scored below the $25 \%$ percentile of a standardized mathematical test, time to complete the auditory, written-visual, and color Trail Making Tests also were related to arithmetic performance (McLean \& Hitch, 1999). The authors concluded that both spatial WM span and switching between retrieval plans (the central executive; Baddeley \& Hitch, 1994) contribute to mathematical proficiency. Bull and Scerif (2001) found that inhibition, WM, and inflexible responding accounted for unique variation in mathematical performance in 7-year-old children, after controlling tor the influences of reading proficiency and intelligence scores.

It is not clear whether executive functions are related to mathematical skills earlier in development. Although some have argued that simple mathematical skills are evident in infancy (e.g., Wynn, 1992), there is a marked emergence of informal mathematical skills during the preschool period, that is, those mathematical abilities that are not learned through formal instruction. For example, Gelman and Gallistel (1978) argued that preschool children possess a fundamental understanding of mathematical principles about counting, such as stable order, one-to-one correspondence, and cardinality, although young children may not fully understand the implications of these principles in various enumeration contexts (e.g., Geary, 1994; Sophian. 1996). During the preschool years, there are significant changes in counting skills and arithmetic problem solving (e.g.. Baroody, 1992; Sophian, 1996) and in spatial and geometric abilitjes (e.g., Newcombe \& Huttenlocher, 2000), which provide the foundation for later mathematical knowledge and procedural competencies gained through formal instruction in the primary grades and beyond (Geary, 1994; Ginsburg, 1989; Rittle-Johnson \& Siegler, 1998).

During this same preschool period, there is a rapid development of executive functions, such as inhibition, WM, and flexibility skills (e.g., Diamond, Prevor, Callender, \& Druin, 1997; Espy, 1997; Espy, Kaufmann, McDiarmid, et al.. 1999; Hughes, 1998; Jacques \& Zelazo, 2001). Therefore, examining the relations between executive functions and emergent arithmetic skills in young children may provide insight into the shared ontogenetic organization of these abilities. One limitation that has hampered such endeavors in young children is the lack of available instruments to assess executive functions, as most standardized preschool tests do not adequately assess diverse executive functions. Tasks adapted from develop- 
mental and cognitive neuroscience investigations offer one fruitful method by which to investigate executive functions (e.g., Diamond, 1985; Espy, Kaufmann, \& Glisky, 1999; Espy, Kaufmann, McDiarmid, et al., 1999). Such tasks are advantageous because their relation to prefrontal cortical function has been established, at least in well-controlled studies with nonhuman animals or using similar neuroimaging paradigms with adult humans.

For example, the relation between the dorsolateral prefrontal cortex and WM is one of the most consistently demonstrated structure-function relations in neuropsychology (Goldman-Rakic, 1987b). WM in monkeys is affected by both cortical, as well as subcortical, experimental manipulations, as evidenced by alterations in performance on the classic delayed response (DR) paradign (Goldman-Rakic, 1987a). Corollary tasks that use reversals of reward contingencies (Mishkin, 1964) also are impaired by lesions to structures in the ventromedial-orbitofrontal circuits. Such tasks are well tolerated by preschool children because of the nonverbal nature, simple manual response demands, and doling out of frequent, tangible rewards (Espy, Kaufmann, McDiarmid, et al., 1999). Furthermore, performance on such procedures differs between age groups in normal preschool children (Espy, Kaufmann, Glisky, \& McDiarmid, 2001), differs in those with presumed prefrontal dysfunction due to phenylketonuria (Diamond et al., 1997) and prenatal cocaine exposure (Espy. Kaufmann, \& Glisky, 1999 ), and is related to individual differences in resting frontal electroencephalogram signals in normal infants (Fox \& Bell, 1990). Such developmental cognitive neuroscience tasks (e.g.. Diamond, 1985; Espy, Kaufmann, McDiarmid, et al., 1999; Welsh \& Pennington, 1988) provide the potential to tap differing executive functions that may have unique relations to emerging mathematical abilities in this age range.

However. both the nature of the organization of executive function and task measurement issues must be considered (Lyon \& Krasnegor, 1996). Although many researchers would agree that executive functions are not unitary (e.g., Miyake, Friedman, Emerson, Witzki, \& Howerter, 2000; Welsh \& Pennington, 1988), there remains considerable controversy regarding which specific constructs are "executive" per se. Such issues are important in their own right, but also inherently affect how executive functions might be related to other functional outcomes. such as mathematics. Furthermore, the selection of specific tests in research batteries to measure salient executive functions most often is based on face validity alone. Because of the interrelated nature of executive function constructs, measures that are included to tap a single executive function construct inevitably demand multiple executive function abilities for proficient performance.

For example, to maintain information in WM for upcoming responding, other information invariably is inhibited (e.g., Diamond, 1985). To flexibly shift responding in the face of contlicting rules requires maintaining the rule in mind and inhibiting prepotent, previous responses. Equating tests (e.g., Wisconsin Card 
Sorting Test [WCST]; Heaton, Chelune, Talley, Kay. \& Curtiss, 1993) to constructs (shifting) on the basis of face validity, rather than on the underlying measurement characteristics, easily can lead to erroneous conclusions because of the correlated nature of executive function constructs. Consistent with fractionated executive function models (e.g., Miyake et al., 2000), multiple executive function components or factors are identified: however, the factors typically are not orthogonal or independemt, but rather share some common variance. Studies that have used factor-analytic techniques that account for shared variance between test performance (e.g., principal components analysis, exploratory and confirmatory factor analysis) routinely identify WM and inhibition executive function constructs (e.g., Espy, Kaufmann, McDiarmid, et al., 1999; Hughes, 1998; Miyake et al., 2000; Pennington, 1997), and commonly a tlexibility or shifting executive function construct (e.g.. Lispy, Kaufmann, McDiarmid, et al., 1999; Hughes, 1998; Pennington. 1997; Welsh, Pennington, \& Groisser, 1991). Other more complex executive function constructs, such as concept formation, planning, problem solving, and judgment, may be identified (e.g., H. S. Levin, Fletcher, et al., 1996; Weish et al., 199 J). Using such analytical procedures to empirically reduce the individual test level data to meaningful, shared executive function constructs may better characterize their contribution to emergent mathematical skills. The purpose of this study, then, was to determine how empirically determined executive functions are related to emergent mathematical proficiency in preschool children. Specifically, inhibitory control (IC),WM, and mental flexibility were hypothesized to predict early mathematical abilities in this age range.

\section{METHOD}

\section{Participants}

To include a wide spectrum of children with varying mathematical proficiencies, two groups of preschool children participated, typically developing and those born preterm at low neurobiological risk. Typically developing preschool children ( $n=$ 66) were between the ages of 2 and 5 years ( $M=4.21$ years, $S D=0.87$ years) and were participating in a larger normative, cross-sectional study of executive function development in this age range (e.g., Espy el al., 200।). Typically developing preschoolers were delivered in normal newborn nurseries and weighed $7.53 \mathrm{lb}$ at birth on average ( $S D=1.17 \mathrm{lb}$ ). None of these children were diagnosed with any neurological, psychiatric, or developmental disorders, determined on the basis of parental report. There were 38 girls and 28 boys. with 20 typically developing children of non-White minority race/ethnicity. Mean matemal education level was 14.62 years $(S D=2.13$ years). The mean score on the Picture Vocabulary subtest of the Woodcock-Johnson Psycho-Educational Battery-Revised (WJ-R; Woodcock 
\& Johnson, 1989), which was used as an estimate of overall intelligence (Sattler, 1992), was 101.61 ( $S D=14.12$ ) for the typically developing youngsters.

Preschool children born preterm $(n=30)$ also were between the ages of 2 and 5 years ( $M=3.76$ years, $S D=1.05$ years) and were participating in an ongoing follow-up study (e.g., Espy et al., 2002) of those born early ( $M$ gestational age at birth = 32.23 weeks; $S D=2.0$ weeks $)$ and of low birth weight $(M=3.76 \mathrm{lb}, S D=0.9 \mathrm{llb})$ at a local neonatal intensive care unit. Participation was restricted to low-risk preterm infants ( 28 to 35 weeks gestational age, with no evidence of Intraventricular Hemorthage > Grade 11, periventricular leukomalacia, seizures, chronic lung disease, or bronchopulmonary dysplasia), to investigate outcome in those who are not at obvious risk for more severe neurodevelopmental sequelae (Hack, Klein, \& Taylor., 1995). There were 19 girls and I 1 boys, with 5 children bom preterm of non-White minority race/ethnicity. Mean maternal education was 14.20 years $(S D=2.16$ years) for those born preterm. Preschoolers born preterm obtained a score of 98.87 on the WJ-R Picture Vocabulary subtest ( $S D=13.35$ ). There were no differences between the typically developing preschoolers and those borm preterm in the proportion of boys and girls, $\chi^{2}(1, N=96)=0.28, p>.05$, in the proportion of children of White versus non-White race/ethnicity, $\chi^{2}(1, N=96)=1.99, p>.05$, in average maternal education level, $F(1,94)=0.80, p>05$, or in the mean WJ-R Picture Vocabulary subtest standard score, $F(1,94)=0.80, p>.05$.

\section{Procedure}

Preschool children were administered a battery of executive function tests in a single session by a trained child clinical graduate student blind to the experimental hypotheses. A fixed order for test administration was used, where tests that used similar materials were separated (e.g., DR format tasks) and tests with different presentation and response formats were interleaved to yield a tast-paced, interesting assessment experience for the child. Children were assessed individually in a quiet room, while the parent or guardian was present in the room completing study forms. To maintain cooperation and interest. short breaks were used when necessary. Test sessions were videotaped for the purpose of later scoring. Parents received compensation for study participation, and the children received a bag of developmentally appropriate toys, stickers, and small items.

\section{Measures}

Applied Problems. This subtest of the WJ-R (Woodcock \& Johnson, 1989) was used to assess emergent mathematical abilities. The WJ-R Applied Problems items are graded in difficulty (empirically determined by Rasch item analyses). Specific mathematical content is mixed, including subitizing, ordinal counting, counting relevant object items among mixed object groups, and simple subtraction 
and addition calculations. The standard administration was used, where the preschool child is shown the pictorial mathematical problem, and then points or says the answer. The resulting standard score was used in the analyses.

Picture Vocabulary. Administration of a complete measure of intellectual ability was too time consuming and not directly related to study hypotheses. Because vocabulary typically is the most highly correlated with overall intellectual ability (Sattler, 1992), a standardized vocabulary measure, the WJ-R Picture Vocabulary subtest (Woodcock \& Johnson, 1989), was included as an estimate of overal] intelligence. The standard score was used in the statistical models.

Because of the fractionated nature of executive function, a battery of tasks was used to assess multiple executive function abilities, including four tasks that use the basic delayed-response setup. For the delayed-response-type tasks, a gray testing board with two drilled lateral wells was used. The wells were covered with two inverted beige coffee cups because they were displaced easily and "neutral" in

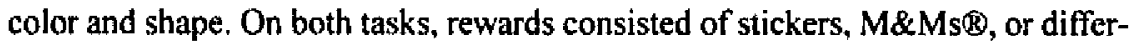
ent cereal bits. Different rewards were used at the beginning of each task. In addition, because young preschoolers are more active and distractible than older children, different rewards also were used when motivation or interest lagged to maximize persistence and facilitate task completion.

Delayed response (DR; Jacobson, Wolfe, \& Jackson, 1935). In this task, the child watched while a reward was hidden in one of the two revealed lateral wells. The cups were replaced simultaneously, and the tray was removed from the child's sight (under the testing table). The examiner counted aloud from 1 to 10 in an engaging manner to distract the child and reduce the use of locational cues that have been shown to improve performance (Diamond, 1988). Then, the testing board was presented to the child after the 10-sec delay. The child was instructed to "Find the reward!" After displacing the selected cup, if correct, the child removed and kept the reward. If the child chose an incorrect location, the examiner encouraged the child to try again on the next trial and did not allow the child to have the reward. Both cups then were removed, and another reward was hidden while the child watched. Rewards were hidden randomly across the left and right wells, in an order consistent across subjects for a total of 17 trials. The total number of correct responses was scored.

DR has been used in many animal studies, but only recently has it been used with humans. Diamond and Doar (1989) concluded that WM and inhibition are necessary to correctly retrieve the reward in DR. DR is similar to A-not-B (Piaget, 1954), which has been demonstrated to load with other measures of WM and inhibition in preschool children (Espy, Kaufmann, McDiarmid, et al., 1999). In DR, the reward is hidden randomly across lateral wells while the child watches, whereas in A-not-B, the reward is hidden is a pattem dependent on the child's re- 
sponse (i.e., the reward is hidden on the same side until the child searches correctly at that location for two consecutive trials, and then the alternate well is baited). DR was selected rather than A-not-B because the number of reversal trials is constant across subjects.

Delayed alternation (DA; Espy, Kaufmann, McDiarmid, et al., 1999). Adapted from studies with primates (e.g., Goldman, Rosvold, Vest, \& Galkin, 1971), DA is considered a measure of WM, consistent with results from studies of nonhuman animals with lesions to dorsolateral prefrontal circuits (Goldman et al., 1971; Watanabe, Kodama, \& Hikosaka, 1997) and work in our laboratory with normally developing preschoolers (Espy, Kaufmann, McDiarmid, et al., 1999). This task was similar to DR and used the same testing board. In DA, however, the reward was always hidden out of the child's sight. To achieve optimal rewards, the child had to alternate retrieval between the left and right lateral wells. Because the location of the reward on subsequent trials was dependent on the child's selection on the previous trial, the child had to maintain the previously rewarded location to guide search behavior on the subsequent trial. First, a pretrial was presented where neither well was baited with a reward, to lead the child to alternate among locations from the outset. After the pretrial, the reward was hidden in the location opposite from the child's last correct response after a $10-s e c$ delay. When the child disrupted the alternation by erroneously searching on the same side, the examiner hid the reward at the same location until correct retrieval occurred, thereby resuming the altemating sequence. Sixteen trials were administered. The number of consecutive perseverative errors was recorded to index the degree of breakdown in WM.

Spatial reversal (SR; Kaufmann, Leckman, \& Ort, 1989). Although SR is similar in administration and format to DA, it does not share significant variance (Espy, Kaufmann, McDiarmid, et al., 1999). Maximal performance requires rule-based learning, presumably similar to the WCST (Heaton et al., 1993), and shifting of performance as rule-based contingencies change (Mishkin, 1964). As in DA, the reward in SR was hidden out of the child's sight, and a 10-sec delay between trials was used. The reward was hidden in the same well on each trial until the child achieved four consecutive correct responses. Then, the opposite well was baited until the criterion of four consecutive correct responses was achieved again. If the child responded incorrectly, the reward remained on the target side until four consecutive correct retrievals were achieved. Sixteen trials were administered. Because optimal SR performance requires attaining a maximum number of sets with a minimum of errors, an efficiency score was calculated by dividing the number of sets attained by the number of errors. 
Spatial reversal with irrelevant color cues (SRC; Espy, Thompson, \& McDiarmid, 2000). Administered directly after SR, SRC was identical in format, except that the cups used to cover the wells differed in color (blue and yellow). The reward continued to he hidden on the same side until the reward was retrieved from that well for four consecutive correct trials. The colored cups were used as a distractor, such that each colored cup covered the left or right well in a random sequence independent of reward location. Optinal performance required the child to ignore the color of the cup while attending to the side on which the reward was found. The number of correct trials required to obtain the first four-trial set was used as the dependent measure.

Six Boxes (Diamond et al., 1997). Six Boxes was an experimental task adapted by Diamond et al. (1997) modeled after the Hamilton Search Task (Hamilton, 1911) that has been used to study WM in nonhuman animals (E. D. Levin \& Bowman, 1986) and the Self-Ordered Pointing Task used to study WM in adult humans (Petrides, 1995). This task originally included two conditions: verbal-spatial and verbal. However, a third condition, spatial, was added for the purposes of this study as Diamond et al. (1997) found that the 4-year-old children performed at ceiling levels on the verbal spatial condition. In each condition, rewards (stickers) were hidden in each of six small boxes while the child watched. The child was asked to lind a reward each time the boxes were presented, with the array of boxes re-presented to the child until all rewards were found. Between trials, the boxes were hidden behind a screen for a 10-sec delay. In the verbal-spatial condition, differently colored and shaped boxes were used to conceal the reward, and these boxes remained in the same location. Therefore, the child could use verbal and spatial information to find the reward. In the verbal condition, the differently shaped and colored boxes were rearranged out of the child's view during the delay between trials; therefore, the child had to use verbal information (shape-color) to find the reward. The spatial condition used six identical white, square boxes that remained in the same location, thereby necessitating the use of spatial location to correctly retrieve the reward. Because 4- and 5-year-old children perform at ceiling levels on the verbal-spatial condition (Diamond et al.. 1997), this condition was not administered unless the participant required more than nine moves to complete the verbal condition. The number of trials to find all rewards was recorded. with an average efficiency score (number of boxes opened divided by number of moves made, averaged across the three conditions) calculated.

Children's Continuous Performance Task (C-CPT). This computerized task was developed by Kerns and Rondeau (1998) as a modification of similar tasks frequently used to measure attention and IC in older children and adults. Overall task duration was reduced, visual stimuli that were engaging and familiar to preschool children were adopted, and animal noises were included as auditory 
stimuli. Children attended to a random grayscale display of several common animals on an Appleß laptop, one at a time, for a total duration of $3 \mathrm{~min}$. Each animal was presented for $1.5 \mathrm{sec}$ and accompanied by an animal sound (e.g., dog barking, horse neighing). The animal sounds were selected randomly and independently of the type of animal, such that the sound did not match the animal presented, except by chance occurrences. The child was familiarized with all the animals and the sounds prior to testing. The child then was instructed to press the button on the computer mouse whenever a target animal (sheep) was presented, regardless of the accompanying noise. A brief trial run $(25 \mathrm{sec})$ was conducted at least once with each participant but was repeated if the child seemed to have difficulty understanding the task demands. Although stimuli were presented randomly, a ratio of six distractors to one target was maintained across participants. The pereentage of commission errors (responses to nontarget stimuli) relative to the total responses was calculated, as Riccio, Reynolds, and Lowe (2001) suggested that commission errors best measure poor modulation of response inhibition.

Visual Attention (VA). In this subtest of the NEPSY-A Developmental Neuropsychological Assessment (NEPSY; Korkman et al., 1998), children were instructed to find items that match the target stimuli among a page of targets and distractors. However, unlike the NEPSY administration, all children completed only one trial, the random array of cats, which is common to both the younger and older NEPSY test forms. Time to locate all target stimuli was recorded, with a 3-min maximum allowed. Efficiency scores were calculated by dividing the number of targets identified by the total number of responses (targets and commission errors).

Statue. In this NEPSY (Korkman et al., 1998) subtest, children stood with their eyes closed and pretended to hold a flag for $75 \mathrm{sec}$. At standard intervals during the $75 \mathrm{sec}$, the examiner attempted to distract the child by making varied noises such as knocking on the table or saying, "Ho hum!" For every 5-sec interval, any body movement, eye openings, or vocalizations were recorded. Two points were scored for every error-free time interval. If the child made only one error in an interval, 1 point was given. The total number of points was tallied and used as the dependent measure.

Self-control (Lee, Vaughn, \& Kopp, 1983). In this task, the child was presented at the conclusion of testing with an attractive wrapped gift. The gift was placed on the table in front of the child, and the child was instructed not to touch the gift until the examiner had finished another task. The examiner then engaged in another activity (e.g., reviewing test sheets or interviewing the parent) while surreptitiously observing the child. The latency to touch the gift (with a maximum of $150 \mathrm{sec}$ ) was recorded. 
Composite scores. First, the raw scores from each task were transformed into $z$ scores using the overall sample mean and standard deviation (depicted in Table 1). Because a lower percentage of commission errors on the $\mathrm{C}-\mathrm{CPT}$, fewer consecutive perseverative errors on DA, and fewer trials to the first set on SRC indicated better performance, the sign of the $z$ scores for these three variables was inverted (multiplied by -1 ) so that all positive $z$ scores indicated superior performance for the purposes of averaging. Construct composite scores then were calculated as the average of all available $z$ scores for tasks that loaded on that principal component (McDiarmid, 2002) derived from the subjects with complete data on all tasks (49\%). Components were determined based on examination of the scree plot and retaining factors witheigenvalues $>$ I (Gorsuch, 1983), using a promax extraction that allowed correlated components. The identified components were consistent across the raw and age-residualized scores, with all tests contributing substantively to a single factor. Variables were assigned to factors if the loading exceeded .50 .

This data reduction strategy was chosen because of the prevalence of missing data. Not surprisingly, task perseverance of younger children was more variable, leading to more missing data for the younger children. Using factor scores from only children with complete data would limit generalization across the entire preschool age range. Therefore, this strategy of calculating composite scores based on the factor-loading pattern allowed the inclusion of preschoolers with missing data but still accounted for the interrelations among executive function measures.

\section{RESULTS}

Sample mean performance on the individual executive function tasks is presented in Table 1. Note the range of performance, with no evidence of floor or ceiling ef-

TABLE 1

Study Sample Executive Function Task Performance

\begin{tabular}{lccc}
\hline Measure & $M$ & $S D$ & \multicolumn{1}{c}{ Range } \\
\hline DA maximum consecutive perseverative crurs & 2.38 & 1.40 & $0.00-7.00$ \\
Six boxes efliciency score & 0.74 & 0.15 & $0.42-1.00$ \\
VA efticiency score & 0.83 & 0.22 & $0.21-1.00$ \\
C CPT \% commission errors & 0.55 & 0.32 & $0.00-0.96$ \\
DR total comect & 13.53 & 2.67 & $6.00-17.00$ \\
Self control latency & 98.54 & 58.48 & $0.00-150.00$ \\
Statue total score & 15.61 & 9.86 & $0.00-30.00$ \\
SRC Irials to first set & 7.84 & 4.39 & $0.00-16.00$ \\
SR efficiency & 0.38 & 0.27 & $0.00-1.00$ \\
\hline
\end{tabular}

Nore. Duc to missing data. $N=751096$, depending on lask. $\mathrm{DA}=$ delayed alteration; $\mathrm{VA}=$ vistal attention subtest: $\mathrm{C}-\mathrm{CPT}=$ Children's Continuous Performance Test; DR = delayed response; $\mathbf{S R C}=$ spatial reversal with irrelevant color cues; $\mathrm{SR}=$ spatial reversal. 
fects. The results from the principal components analyses are depicted in Table 2 . Three factors were extracted, accounting for $60.82 \%$ of the variance. The first identified principal component accounted for $26.59 \%$ of the variance and was labeled working memory (WM), composed of efficiency scores from Six Boxes and VA (both loadings positive in sign), along with the maximum number of consecutive perseverative DA errors (loading negative in sign). The $\mathrm{IC}$ composite was composed of the $\mathrm{C}-\mathrm{CPT}$ percentage commission errors, the total number correct on DR, the latency to touch on Self Control, and the Statue total score, accounting for $19.39 \%$ of the variance. Finally, the third identified component $(14.84 \%)$ was labeled shiff. composed of the number of trials to the first set on SRC and the SR efficiency score. These executive function composite scores then were computed as described, based on these factor-loading pattern, and then used as the relevant predictors of emergent mathematical skills and in comparisons between groups.

Bivariate correlations between the executive function composite scores and pertinent sample characteristics are depicted in Table 3. Results revealed that both matemal education and child vocabulary score were related to early mathematical competency (the dependent measure) and to some executive function composite scores (the independent variables). Furthermore, the executive function composites were not standardized with respect to age, and therefore, age also was included as a covariate in the predictive models. To test the study hypotheses, several hierarchical regression analyses were conducted. First, each executive function composite was entered in the regression model after controlling for age, with separate analyses for each executive function composite score. Then, similar models were run with each executive function composite score entered after age and the other

TABLE 2

Executive Function Component Structure Identified in Principal Components Analysis

\begin{tabular}{lccc}
\hline Task (Variable) & Working Memory & Inhibitor Control & Shifting \\
\hline DA (maximum consecutive & .75 & - & - \\
$\quad$ perseverative errors) & .74 & - & - \\
Six boxes (efficiency score) & .90 & - & - \\
VA (efficiency score) & - & .61 & - \\
C-CPT (\% commission errors)" & - & .58 & - \\
DR (total correct) & - & .75 & - \\
Self-control (latency to touch) & - & .69 & - \\
Statue (total score) & - & - & .65 \\
SRC (trials to firsi set) & - & - & .74 \\
SR (efficiency score) & & & \\
\hline
\end{tabular}

Nole. All factor loadings $>.50$ are displayed. $\mathrm{DA}=$ delayed alturation: $\mathrm{VA}=$ visual attention subtest: $\mathrm{C}-\mathrm{CPT}=$ Children's Continuous Performance Test; $\mathrm{DR}=$ delayed response; $\mathrm{SRC}=$ spatial reversal with irrelevant color cues: $S R=$ spatial reversal.

aReverse scored such that higher scores indicate more optimal performance. 
TABLE 3

Bivariate Correlations Among Dependent, Independent, and Covariate Measures

\begin{tabular}{lcccccc}
\hline Variables & $K$ & $W M$ & Shifring & Age & Mal Ed & WJ-R PJSS \\
\hline WJ-R APSS & $.55^{* * * *}$ & $.31^{* *}$ & -.08 & .12 & $.37^{* * *}$ & $.57^{* * * *}$ \\
IC & & $.50^{* * * *}$ & .05 & $.50^{* * * *}$ & .20 & $.36^{* * *}$ \\
WM & & & -.01 & $.67^{* * * *}$ & $.24^{*}$ & .17 \\
Shifting & & & & .07 & .00 & -.11 \\
Age & & & & & .14 & .04 \\
Mat Ed & & & & & & $.29^{* *}$ \\
\hline
\end{tabular}

Note. $\quad N=96 . \mathrm{IC}=$ inhibitory control composite $z$ score; $W M=$ working memory composite $z$ score: Mat Ed = matemal education level in years; WJ-R = Woodcock-Johnson-Revised Psychoeducational Battery: PVSS $=$ Picture Vocabulary standard score: APSS $=$ Applied Problems standard score.

$$
* p<.05 . * * p<.01 .{ }^{* * *} p<.001{ }^{* * * * p} p<.0001 \text {. }
$$

covariates (i.e., the child's score on the WJ-R Picture Vocabulary subtest and matemal education level) that were included as a block. To determine the relative contribution of each executive function composite beyond that of the two other executive function composites (e.g., unique contribution of WM to mathematical skills, beyond that of IC and shift), models included age and the two covariates, then the two remaining executive function composite scores, and finally, the executive function composite score of interest.

Contained in Table 4 are the results from the regression analyses relating performance on the executive function composites to emergent mathematical abilities. After statistically controlling for the influence of age, higher scores on the $\mathrm{lC}$ and on the WM composites were related to greater mathematical proficiency on the WJ-R Applied Problems subtest, $F(1,93)=45.13, p<.000 \mathrm{l}$, and $F(1,93)=$ $9.51, p<.001$, respectively. These relations persisted when the influences of the two covariates, matemal education level and child's score on the WJ-R Picture Vocabulary subtest, also were included in the models; for IC, $F(1,91)=25.36, p<$ .0001 , and for WM, $F([, 91)=4.52, p<.05$. In both models, the IC composite accounted for the largest portion of the variance in preschool mathematical skils, $32 \%$ in the only age-controlled model and $14 \%$ in the age- and covariate-controlled model, respectively. The relation between the $\mathrm{IC}$ composite score and the WJ-R Applied Problems subtest standard score is depicted in Figure 1. The inclusion of the covariates affected the relation between WM composite performance and early mathematical skills more than that of $[C$ composite scores and mathematics, as the difference in the proportion of variance attributed to WM was reduced by $80 \%$ between the two models, in contrast to a $50 \%$ reduction for IC. The magnitude of the unstandardized regression weights indicated that the difference in WJ-R mathematical proficiency was 9.65 points between children who scored 
TABLE 4

Contributions of Executive Functions in Emergent Mathematics Skills

\begin{tabular}{lcrcc}
\hline Variables & $R^{*} \Delta$ & $F$ & $b$ & $\beta$ \\
\hline 1. Age controlled & & & & \\
1 a. Inhibitory control & $.32^{* * * *}$ & 45.13 & $13.70^{* * * *}$ & $0.65^{* * * *}$ \\
1 b. Working memory & $.17^{* * *}$ & 9.51 & $8.61^{* * *}$ & $0.41^{* * *}$ \\
I c. Shifting & .01 & 0.77 & -2.05 & -0.09 \\
2. Age + covariates controlled & & & & \\
2 a. Inhibitory control & $.14^{* * * *}$ & 25.36 & $9.65^{* * * *}$ & $0.46^{* * * *}$ \\
2 b. Working memory & $.03^{*}$ & 4.52 & $5.02^{* * *}$ & $0.24^{*}$ \\
2 c. Shifting & .00 & 0.14 & -0.70 & -0.03 \\
3. Age + covariates + other EF composites controlled & & & & \\
3a. Jnhibitory control & $.12^{* * * *}$ & 22.18 & $9.23^{* * * *}$ & $0.44^{* *}$ \\
3. b. Working memory & .01 & 0.17 & 2.85 & 0.14 \\
3 c. Shifting & .00 & 0.45 & -1.12 & -0.05 \\
\hline
\end{tabular}

Note. $\quad N=96$. Covariates $=$ matemal education and child picture vocabulary subtest standard score. EF $=$ executive functioning. Each model was run separately for each dependent variable,

$* p<.05{ }^{* *} p<.01 .{ }^{* * *} p<.001 . * * * p<.0001$.

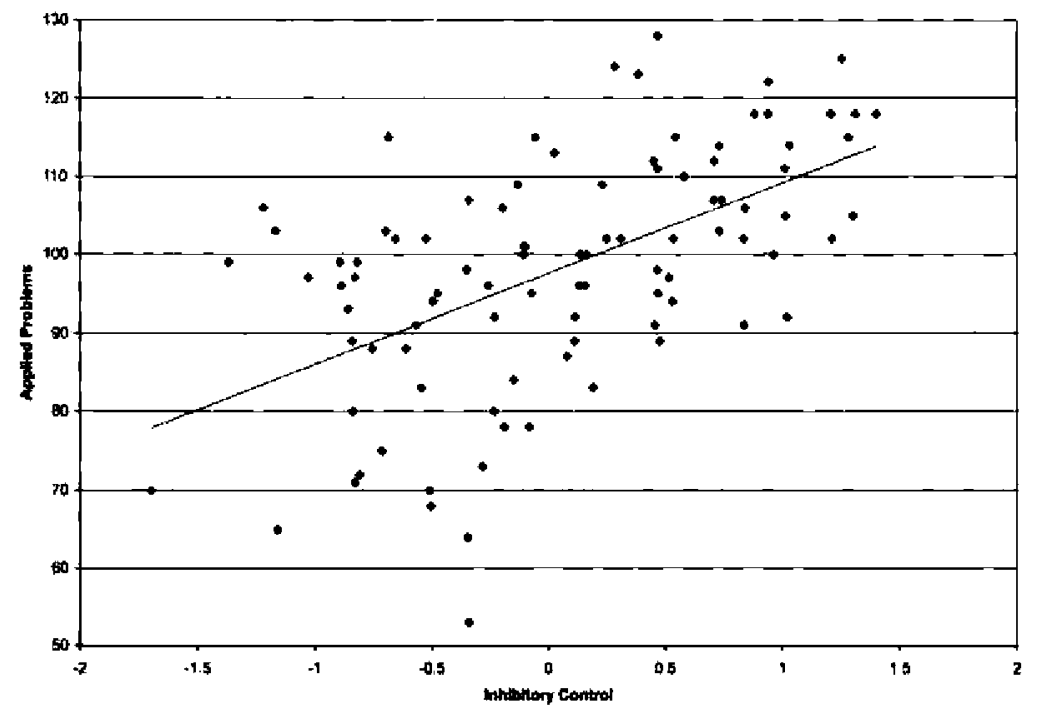

FIGURE 1 Woadcock-Johnson-R Applied Problems standard score as a function of $\mathrm{IC} z$ score in preschool children. 
at the mean (expected score $=98.24$ ) on the IC composite and those who scored 1 $S D$ below the mean (expected score $=88.59$ ), after accounting for child age, maternal education level, and child vocabulary score. Correspondingly, the difference in expected score on the WJ-R Applied Problems subtest between children who scored at the mean on the WM composite and those who scored I $S D$ lower was -5.02 points. Shift composite scores were unrelated to WJ-R mathematical proficiency in the age-controlled $F(1,93)=0.77, p>.05$, and age- and covariate-controlled models, $F(1,9])=0.14, p>.05$.

Because scores on the executive function composites were intercorrelated, further analyses were conducted to examine the unique contribution of each executive function composite, beyond that of the remaining executive functions. The models included age, the two covariates, the remaining two executive function composite scores, and finally, the executive function composite score of interest. These results are displayed in the bottom of Table 4 . Only performance on IC composite accounted for unique variability (12\%) in emergent mathematical abilities on the WJ-R, beyond that of both WM and shift composite scores, $F(1$, $89)=22.18, p<.0001$. The difference in WJ-R Applied Problems scores between children who scored at the mean and those who scored $1 S D$ below the mean was -9.23 points. Neither WM, $F(1,89)=1.69, p>.05$, nor shift, $F(1,89)$ $=0.45, p>.05$, composite scores were related independently and uniquely to emergent mathematical abilities.

\section{DISCUSSION}

Specific executive functions, namely WM, IC, and shifting, were determined empirically, based on shared variance across individual tests. In turn, executive functions were related to emergent mathematical proficiency in preschool children. Both IC, and to a lesser extent WM, contributed substantively to mathematical performance in this age range. These findings provide a developmental link to similar relations between executive function and mathematical performance previously reported in school-age children (e.g., Bull \& Scerif, 2001; Gathercole \& Pickering, 2000; McLean \& Hitch, 1999). Given the differences in age range. methods used, and design between this study and others, the consistency of the relation of executive functions and mathematical performance is persuasive.

Specifically, the contribution of IC to early mathematical skills was central in preschoolers. Here, the magnitude of the relation to mathematics was large, even when the effects of child age, estimated child verbal intelligence, and maternal education level were controlled statistically. Furthermore, IC predicted emergent mathematical skills in preschool children when the influences of WM and shifting were removed, still accounting for $12 \%$ of mathematical skill variability. In contrast, Bull and Scerif (2001) found that in 7-year-old children, inhibition (as- 
sessed by Stroop Interference scores) accounted for only $2 \%$ of the unique variance (marginally significant) in mathematical performance, after controlling for estimated intelligence, reading skills, WM, and perseverative responding. These relative differences in the magnitude of the effect of IC are particularly salient, as in both studies, the predictive models accounted for a comparable overall percentage of mathematical performance variability $\left(R^{2}=52 \%\right.$ in our study, $\mathrm{R}^{2}=$ $62 \%$ in Bull \& Scerif, 2001).

In preschool children, IC typically is measured by tasks that require inhibition of a motor response. For example, pushing a button when a target animal is presented, but not pressing the response key when the animal's sound is paired with the incorrect animal picture; maintaining a still posture despite distractions; inhibiting reaching for an enticing gift; and inhibiting searching at a previously rewarded location. In contrast, in school-age children, inhibition more often is measured by tasks that require a stronger cognitive inhibitory component, such as the Stroop Interference that was used by Bull and Scerif (2001). The relations between the more primitive, "motorically"-based IC and the later, more "cognitive" inhibition is not clear. Ruff and Rothbart (1996) conceptualized IC as a developmental precursor to the cognitive inhibition, but such relations have not been demonstrated empirically. Until such relations are clarified further with longitudinal designs, the ontogenetic relation between IC and the developmental of mathematical competency will not be elucidated fully.

Several investigators (Bull \& Scerif, 200I; Gathercole \& Pickering, 2000; McLean \& Hitch, 1999) have noted the role of WM in mathematics in older school-age children. In preschoolers, WM accounted for significant variance in early mathematical proficiency, when the influences of child age, estimated child verbal intelligence, and matemal education level were controlled. However, in this age range, WM skills were correlated substantially with $\mathrm{IC}(r=.50, p<.0001)$, limiting the amount of unique variance in emergent mathematical skills that could be accounted for by WM. The high correlation between performance on the IC and WM composites in the preschool children studied here differs from the nonsignificant relation (magnitude not reported) between WM and inhibition in school-age children reported by Bull and Scerif (2001). In preschool children, IC and WM may be more "intertwined" or less differentiated, reducing the unique contribution to mathematical proficiency in comparison to that of older children.

Unfortunately, other investigators who have examined the relation between WM and mathematical performance in school-age children (Gathercole \& Pickering, 2000; McLean \& Hitch, 1999) did not include tests that were designed to measure other specific executive functions. Instead, in these studies, the Baddeley and Hitch (1994) model was used, where WM was parsed into the central executive, visual spatial sketch pad, and phonological loop. Complicating the characterization of the relation between WM and executive function abilities is the lack of a shared definition of executive function. For example, in 
Gathercole and Pickering (2000), counting span (Case, Kurland, \& Goldberg, 1982) was chosen to assess the central executive, and other more visual spatial tasks were used to measure the visuospatial sketch pad. In McLean and Hitch (1999). Corsi blocks (Milner, [971), another span-type task, was chosen as a measure of the visuospatial sketch pad, where several Trail Making Test-type tasks were used to measure the central executive. Finally, Bull and Scerif (2001) used counting span to measure WM. Span tasks probably tap short-term memory storage capacity rather than WM per se, when WM is defined as maintaining information online for further processing or responding (Fuster, 1989).

Interestingly, shifting or mental flexibility did not contribute to mathematical skills in preschool children. These findings are in contrast to those reported for school-age children (Bull \& Scerif, 2001; McLean \& Hitch, 1999). Mental flexibility may have contributed more to mathematical abilities in older children, given the necessity for the child to flexibly apply different mathematical procedures (e.g. borrowing, carrying) to obtain correct mathematical solutions. More complex mental flexibility skills also may be later developing and, thus, may be less related to mathematical performance in preschool children. However, the measurement of cognitive flexibility in preschool children has proved to be challenging. Reversal task performance may discriminate only those with severe disturbances in flexibly shifting between response sets, for example, children diagnosed with severe disorders such as autism (McEvoy, Rogers, \& Pennington, 1993). Other measures that focus on concept formation may prove to be more useful in this regard (e.g., Jacques \& Zelazo, 2001; Smidıs, Jacobs, \& Anderson, this issue).

These observed relations may be related to the type of mathematical problems that preschool children can solve. In school-age children even as young as age 7 years, mathematical problems likely require maintaining information online for subsequent processing and responding. For example, children must recall mathematical facts to use for carrying and borrowing. In contrast, mathematical problems for preschool children involve counting and simple regrouping, which, at least on the surface, do not demand as much WM skills to achieve adequate proficiency. In fact, most of the early items from the WJ-R Applied Problems subtest can be solved with knowledge of small-quantity numbers (National Institute of Child Health and Human Development, 2002). Not surprisingly, more proficient performance on these simple problems likely requires more basic IC, as was observed here. Using multiple measures of mathematical abilities will be important to determine how executive functions are related to more complex mathematical skills that involve, for example. reasoning. time calculation, and measurement. Longitudinal studies that dynamically relate the development of executive control and mathematical skill development in multiple arenas across primary grades is necessary.

One strength of the approach used here is the empirical derivation of the composites (McDiarmid, 2002) to assess the executive functions of interest. Three 
components were extracted, labeled as WM, IC, and mental flexibility, consistent with other studies in older children (e.g., Kelly, 2000; H. S. Levin, Fletcher, et al., 1996; Pennington, 1997; Welsh et al., 1991). Generally, the measurement pattern was consistent with expectations, although the loading of DR with the other instruments on the IC factor was somewhat surprising, as was the loading of the NEPSY VA subtest on the WM factor. Although this observed measurement pattern was derived empirically, the labels applied are a matter of individual preference and judgment. The labels were applied on the basis of previous findings and historical context; however, other labels from other frameworks also might easily describe the derived factors. Furthermore, another disadvantage of this statistical approach is that the loading pattern results are test specific, where the specific pattern might have varied if different dependent variables, even from the same task, had been selected for inclusion.

What is needed are systematic studies that use measurement model approaches to better characterize executive function organization in children (e.g. confirmatory factor analysis), similar to what was initiated by Miyake et al. (2000) in college students. Although the executive function composites used here were derived empirically, structural equation modeling approaches are preferred, which can more accurately represent the relations annong observed test performance and the latent constructs. Such studies are more difficult to conduct in young children who cannot complete long batteries of tests that are necessary to fully define the latent constructs, commonly resulting in missing data that limits participant inclusion. This issue was apparent here, where the executive function components were calculated from subjects with complete data only, not surprisingly, largely in older preschool participants. A different loading pattern might have resulted if all children could have been included in these analyses. Because missing data is a common occurrence in studies with young children and those with clinical conditions, the use of imputation procedures (e.g., Allison, 2001; Schafer, 1997) or different modeling estimation procedures that are not used commonly in neuropsychology may be necessary to fully use data from such participants. These procedures must be applied with care, however, as the underlying cognitive construct also may be rapidly maturing, in some cases, leading to different loading patterns at different ages. Only by understanding executive function organization in different age ranges will it be possible to better describe the resultant relations to other functional outcomes, such as mathematical proficiency.

Another study limitation is the sampling strategy. Children born preterm at low risk for neurodevelopmental sequelae were sampled to increase performance variability and power to detect relations between executive function and emergent mathematics by including children more likely to experience later mathematical difficulties. The observed findings, including the resulting test to construct loading pattern, might have differed in a more homogenous sample. All children included here were born at 28 weeks gestation or more, with a much lower risk of adverse 
cognitive sequelae than those born earlier in gestation or at lower birth weights (Hack et al., 1995). Therefore, these findings likely do not represent how executive function may relate to emergent mathematical ability in preschool children born preterm, more broadly. Future studies that focus exclusively on the relation between executive function and emergent mathematical skills in those born preterm across the full spectrum of neurobiological risk are critical to better understand outcome in this important population.

The relation between executive function and mathematical proficiency suggests an important role of prefrontal cortical circuits in this age range, consistent with findings from recent imaging studies in adults and children relating to various mathematical skills and frontal lobe function (Fullbright et al., 2000; Gruber et al., 2001: H. S. Levin, Scheller, et al.. 1996; Menon et al., 2000; Miles \& Stelmack, 1994; Prabhakaran et al., 2001; Zago et al., 2001). However, without direct measurement of brain function and concurrent behavioral assessment in this age range, the specific areas that contributed to emergent mathematical proficiency in preschool children are unknown. Because of the technical limitations of the use of functional imaging methods with young children, high-density sensor array, event-related potential methods may be more suitable tools by which to examine such relations in young children.

More generally, the use of developmental and cognitive neuroscience paradigms in preschool children offer the opportunity to better assess more discrete neuropsychological skills that are related to functional outcome, such as emergent mathematical proficiency. However, there may be test-specific issues, such as test administration order that were not controlled here, which may have affected the noted findings. Nevertheless, such methods are particularly appealing, as the relation of test performance to specific brain areas may be stronger than more traditional general ability measures. Although the neuropsychological structure in preschool children likely is less differentiated than in older children, these methods are useful in highlighting executive function performance discrepancies that relate to functional academic outcome. Even in modem investigations that focus on direct brain measurement with highly specialized and technical methods, the careful description of behavior-behavior relations across the developmental context (Fletcher \& Taylor, 1984) still is relevant today.

\section{ACKNOWLEDGMENTS}

This research was supported, in part, by the Pediatric Neuropsychology/Developmental Cognitive Neuroscience Award from the Rita Rudel Foundation and the Special Research Program Award from the Southern Illinois University Office of Research Development and Administration to Kimberly Andrews Espy. 
We thank the participating families, undergraduates who assisted in various laboratory tasks associated with this study, and Diana Mitchell for her assistance with data collection.

\section{REFERENCES}

Allison, P. (2001). Missing data. Thousand Oaks, CA: Sage.

Baddeley, A. D., \& Hitch, G. J. (1994). Developments in the concept of working memory. Neuropsychology: 8. 485-493.

Baroody. A. J. ( 1992). The development of preschoolers' conuting skills and principles. In J. Bideau, C. Meljac, \& J. Fischer (Eds.), Parhwavs to mumber (pp. 99-126). Hiltsdale, NJ: Lawrence Erlbaum Associates, Inc.

Bull, R., \& Scerif, G. (2001). Executive functioning as a predictor of children's mathematics ability: Inhibition, switching, and working memory. Developmental Neuropswchology: 19. 273-293.

Case, R., Kurland, D. M., \& Goldberg. J. (1982). Operational effietency and the growth of shor-term memory span, Journal of Experimental Child Psychology: 33, 386-404.

Cirino, P. T., Morris, M. K., \& Morris, R. D. (2002). Neuropsychological conconitants of calculation skitls in college students referred for learning difficulties. Developmental Nenropsychologu. 21. $201-218$.

Diamond, A. (1985). Development of the ability to use recall to guide action, as indicated by infants" performance on AB. Child Development. 56, 868-883.

Diamond. A. (1988). Abilities and neural mechanisms underlying AB performance. Child Development, 59. 523-527.

Diamond, A., \& Doar, B. ( 1989 ). The performance of human infants on a measure of frontal cortex function, the delayed response task. Developmenal Psychobiology. 22. 271-294.

Diamond, A.. Prevor, M. B., Callender. G.. \& Druin. D. P. (1997). Prefrontal conex cognitive deficits in children treated early and continuously for PKU. Monogrophs of the Socicty for Research in Child Development. 62(4), I-205.

Espy, K. A. (1997). The Shape School: Assessing executive function in preschonl children. Developmental Neuropsycholugy: 13. 495-499.

Espy, K. A.. Kaufmann. P. M., \& Glisky. M. L. (1999). Neuropsychological function in toddlers exposed to cocaine in utero: A preliminary study. Developmemol Kentrpsychologi: $15,447-460$.

Espy, K. A., Kautmann, P. M., Glisky, M. L., \& McDiarmid, M. D. (2001). New prucedures to assess exectrive functions in preschool children. Clinical Neuropsychologist. 15; 46-58.

Espy, K. A., Kaufinann, P. M. McDiamid, M. D., \& Glisky, M. L. (1999). Executive lunctioning in preschool children: Performance on A-not-B and other delayed response format tasks. Brain and Cognition, 41. 178-199.

Espy, K. A., Stalets, M. M., McDiarmid, M. D., Senn, T. E., Cwik. M. F. \& Hamby, A. F. (2002). Executive functions in preschool children born preterm: Applications of cognitive neuroscience paradigms. Child Neuropsuchology: $8,83-92$.

Espy. K. A., Thompson, E.. \& McDiarmid. M. D. (2000). Spatiul reversal with irrelevant culor cues. Unpublished test.

Fletcher, J. M., \& Taylor. H. G. (1984). Neuropsychological approaches to children: Towards a developmental neuropsychology. Journul of Climical Neuropsycholog: 6, 39-56.

Fox, A. A., \& Bell, M. A. (1990). Electrophysiological indices of trontal lobe development: Relations to cognitive and affective behavior in human infants over the first year of life. Ammals of the New York dcademy of Sciences. 608. 677-698. 
Fullbright, R. K.. Molfese. D. L.. Stevens, A. A.. Skudlarski, P., Lacadie, C. M., \& Gore. J. C. (2000). Cerebral activation during multiplication: A functional MR imaging study of number processing.

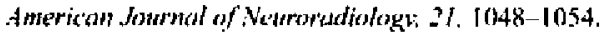

Fuster, J. M. (1989). The prefrontal corter: Anatomy, physiology and netwopsychologi of the frontat lobe (2nd ed.). New York; Raven.

Gatherenle, S. E. \& Pickering. S. J. (2000). Working memory delicits in children with low achievements in the national curriculum at 7 years of age. British dournal of Educurional Psychologv. 70 . $177-194$.

Geary, D. C. 1 1994). Children st mathematic d developmem. Washington. DC; American Psychological Association.

Gelman. R., \& Gallistel. C.R. (1978). The child's understanding of momber. Washington, DC: American Psychological Association.

Ginsburg, HI. P. (1989). Children S arithectic (2nd ed.). Cambridge. MA: Harvard University Press.

Goldman, P. S.. Rosvold, H, E. Vest, B., \& Galkin. T. W, (1971). Anulysis of the delayed-alternation deticit produced by dorsolateral prefirontal lesions in the rhesus monkey. Soumal of Comparative and Physiological Psuchologlt 77, 212-220.

Gioldman-Rakic, P, S. (1987a). Circuitry of primate prefrontal contex and regulation of behavior by representational menory. In F. Plurn \& V. Mountcastle (Eds.). Handhook of physiologr (Vol. 5, pp. 373 417). Bethesda. MD: Ameritan Physiological Asseciation.

Goldman-Rakic, P. S. (1987b). Development of contical cireuitry and cognitive function. Child Develonment. $58,601-622$.

Gorsuch, R. L. (1983). Facror amalysis (2nd ed.). Hillsdale, NJ: Lawrence Erlbaum Associates, Inc.

Gruber, O., Indefrey, P., Steinmetz, H., \& Kleinschmid, A. (200) ). Dissuciating neural correlates of cognitive components in mental calculation. Cerdbral Cortex, $11,350-359$.

Hack, M., Klein, N. K., \& Jaylor, H. G. (1995). Long-term developmental outcomes of Jow birth weight infunts. Furure of Children, 5, 176-196.

Hanitton, G. V. (1911), A study of trial and ertor reactions in mammals. Journal of Animal Behavior. (1). 33-66.

Ileaton, K. K., Chelune, G. J.. Talley, J. L.. Kay, G. G. \& Curtiss, G. (1993), Misconsin Card Sorting Test mumul. Odessa. FL: Psyehological Assessment Resources.

Hughes, C. (1998). Executive tunction in preschoolers: Links with theory of nind and verbal ability. British Journat of Developmental Patchologl; 16. 233-253.

Jacobson, C. F.. Wolfe, J. B., \& Jackson, T. A. (1935). An experimental analysis of the functions of the frontal association areas in prinales. Journal of Nervous and Mental Disease, $82.1-14$.

Jacques, S., \& Z.elazo, P. D. (2001). The Flexible Item Selection Jask (FIST): A measure of executive function in preschoolers. Developmental Nemropsichologr. 20. 573-591.

Kaufimann. P. M. Leckman, I. M., \& Or. S. I. (1989). Delayed response performance in males with Fragile-X. Jurrial of Clinical and Experimental Veuropsichologn, 12,69

Kelly, T. P. $(2000)$. The development of executive function in school-aged shildren, Clinical Neuropsychological Assewsment. 1. 38-55.

Kerns, K. A., \& Rondeau. L. A. (1998). Development of a coutinutsus performance test for preschool children. Journal of Attention Disorters, 2, 229-238.

Korkman. M., Kirk. LI., \& Kemp. S. (1998). WEPSY t developmenol neumpswchological assessment manual. San Antonio. TX: Psychological Corporation.

Lee. M., Vaughn, B. F.. \& Kopp. C. B. (1983). Role of self-controt in the performance of very young children on a delayed-response menory-for-lowation task. Developmenal Psychology: 19. $40-44$

Levin. F. D. \& Bowman, R. E. (1986). Long-tem lead ctfects on the Hamilton Search Task and delayed alternation in monkeys. Neturthohaviral Towicolugl of Teralology: 8. 219-224. 
Levin, H. S., Fleteher, J., Kutera, J., Harward, H., Lilly, M., Mendelsohn, D., el al. ( \$996). Dimensions of cognition measured by the Tower of London and other cognitive tasks in head-injured children and adolescents. Denelopmentul Nearopsychologv. 12, 17-34.

Levin. H. S., Scheller, J., Grafman. J., Martinkowski, K., Winslow, M., \& Mirvis, S. (1996). Dyscalculia and dyslexia after right hemisphere injury in infancy. Archives of Neurolog! $53.88-96$.

Lyon. G. R., \& Krasnegor, N. A. (Eds.). ( 1996). Attention. memory and executive function. Baltimore: Brookes.

McDiamid. M. D. (2002). The relarion benween low-level lead exposure and aftention in preschool children. Unpublished doctoral dissenation. Southem Illinois University, Carhondale.

McEvoy, R. E., Rogers, S. J.. \& Pennington. B. F. (1993). Execurive function and social communication deficits in young autistic children. Jolernal of Child Psychology and Pspchiatry and Allied Disciplines. 34. 563-578.

McLean, J. F.. \& Hitch, G. J. (1994). Working memory impainnents in children with specific arithmelic learning difficulties. Journal of Experimental Clinical Psychology, 74, 240-260.

Menon, V., Riveria, S. M., White, C. D., Glover, G. H., \& Reiss, A. L. (2000). Dissociating preftontal and parietal cortex activation during arithmetic processing. Physical Review Letters, 85. 520-524.

Miles, J. \& Stelmack. R. M. (1994). Leaming disability subtypes and the effects of auditory and visual priming on visual event-related potentials to words. Journal of Clinical \& Experimental Neuropsycholog: 16, 43-64.

Milner, B. ( 971$)$. Interhemispheric differences in the localization of psychological processes in man. British Medical Bulletin. 27, 272-277.

Mishkin. M. (1964). Perseveration of central sets after frontal lesions in monkeys. In J. M. Warren \& K. Akert (Eds.). The fronfal granular corter and behavior (pp. 219-241). New York: McGraw-Hill.

Miyake, A., Friedman, N. P., Emerson, M. J., Witzki, A. H., \& Howerter, A. (2000). The unity and diversity of executive functions and their contributions to complex "frontal lobe" tasks: A latent variable analysis. Cognitive Psychologi: 4l. 49-100.

National Institute of Child Health and Human Development (2002, Outober). Workshop. "Early Childhood Education and School Readiness." Baltimore. MD.

Newcombe. N.. \& Huttenlacher, J. (2000). Muking space: The detelopment of spatial representation and reasoning. Cambridge. MA: MIT Press.

Pennington. B. F. (1997). Dimensions of executive functions in normal and abnormal development. In N. A. Krasnegor, G. R. Lyon, \& P. S. Goldman-Rakic (Eds.), Development of the prefrontal corter (pp. 265-281). Baltimore: Brookes.

Petrides. M. (1995). Impairments on nonspatial self-ordered and externally ordered working memory tasks after lesions of the mid-dorsal part of the lateral frontal cortex in the monkey. Journal of Neuroscience, 15, 359-375.

Piaget, J, (1954). The construction of reality in the child. New York: Basic Books.

Prabhakaran, V., Rypma, B., \& Gabrieli, J. D. E. (200I). Neural substrates of mathematical reasoning: A functional magnetic resonance imaging study of neoconical activation during performance of the necessary arithmetic operations test. Neuropsychology: 15, 115-127.

Riccio, C. A., Reynolds, C. R., \& Lowe, P. A. (2001). Clinical applications of continuous performance tests: Meassring altention and impulsive responding in children and adults. New York: Wiley.

Rittle-Johnson, B., \& Sieglet. R. S. (1998). The relationship between conceptual and procedural know]edge in learning mathematics: A review. In C. Donlan (Ed.). The development of mathematical skills (pp. 75-1 10). East Sussex. England: Psychology Press.

Ruff, H. A., \& Rothbar. M. K. (1996). Altention in early development: Themes and variations. New York: Oxford University Press.

Sattler, J. M. ( 1992). Assexsment of children (3rd ed.). San Diego: Sattler.

Schafer, J. L. (1997). Analysis of incomplere multivarjate dafa. London: Chapman \& Hall. 
Smidts, D. P., lacobs, R., \& Andersort, V. (2004/this issue). The Object Classification Task for Children (OCTC): A measure of concept generation and mental flexibility in early childhood. Developmental Neuropsychology: 26, 385-401.

Sophian, C. (1996). Children 's numbers. Boulder, CO; Westview:

Watanabe, M., Kodama, T., \& Hikosaka, K. (1997). Increase in exiraceilular dopamine in primate prefiontal cortex during a working memory task. Journal of Neurophysiology: 78, 2795-2798.

Wetsh, M.C., Pennington, B. F. (1988). Assessing frontal lobe functioning in children: Views from developmental psychology. Developmental Neuropsychologu. 4, 199-230.

Welsh, M. C., Pennington, B. F., \& Groisser, D. B. (1991). A normative-developmental study of executive function: A window on prefrontal function in children. Developmentol Neuropsychology. 7. $131-149$.

Woodcock. R. W. \& Johnson. M. B. (1989). Whodcock-Johnson Psycho-Educurional Batrery-Relised. McAllen, TX: DLM.

Wynn, K. (1992). Addition and subtraction by human inlamts. Nature, 358. 749-750.

Zago, L., Pesenti. M., Mellet. E., Crivello, F.. Mazoyer. B., \& Tzourio-Mazoyer, N. (2001). Neural correiates of simple and complex mental calculation. Neursimage, 13. 314-327. 